\title{
Um estudo sobre influenciadores digitais: comportamento digital e identidade em torno de marcas de moda e beleza em redes sociais online
}

\section{A study on digital influences: digital behavior and identity around fashion and beauty brands on online social networks}

\author{
Jenifer Daiane Grieger ${ }^{1}$, Rodrigo Eduardo Botelho-Francisco ${ }^{1}$ \\ ${ }^{1}$ Universidade Federal do Paraná, Curitiba, PR, Brasil
}

Autor para correspondência/Mail to: Jenifer Daiane Grieger, jeniferd.grieger@gmail.com

Financiamento/Funding: Fundação Araucária e Governo do Estado do Paraná

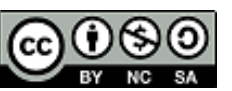

Copyright (c) 2019 Grieger \& Botelho-Francisco. Todo o conteúdo da Revista (incluindo-se instruções, política editorial e modelos) está sob uma licença Creative Commons Atribuição-NãoComercial-Compartilhalgual 3.0 Não Adaptada. Ao serem publicados por esta Revista, os artigos são de livre uso em ambientes educacionais, de pesquisa e não comerciais, com atribuição de autoria obrigatória. Mais informações em http://revistas.ufpr.br/atoz/about/submissions\#copyrightNotice.

\begin{abstract}
Resumo
Este projeto se propõe a estudar os influenciadores digitais, identificando e descrevendo como se dá a construção identitária em torno de marcas do segmento de moda e beleza brasileiras na Internet promovidas por influenciadores digitais. Os influenciadores digitais usam seus perfis para conversar com seu público sobre pautas cotidianas, o que inclui hábitos de consumo, comportamentos, estilo de vida etc. Propondo um estudo exploratório, utilizando como instrumento a netnografia, que trata das mediações tecnológicas adotadas no contexto social e transpostas para os ambientes digitais em rede aos procedimentos clássicos da pesquisa, o estudo tem objetivo de: 1) compreender a configuração atual do mercado de influenciadores de redes sociais online no segmento de moda e beleza no Brasil; 2) investigar o comportamento digital de influenciadores digitais e seus seguidores; 3) analisar as interações entre seguidores e influenciadores digitais; 4) identificar e caracterizar elementos de construção identitária em torno de marcas a partir das interações entre influenciadores e outros atores sociais na rede.
\end{abstract}

Palavras-chave: Influenciadores digitais; Redes sociais; Comportamento digital.

\begin{abstract}
This project aims to study the digital influencers, identifying and describing how the identity construction around Brazilian fashion and beauty brands on the Internet promoted by digital influencers. Digital influencers use their profiles to talk to their audience about everyday guidelines, which include consumer habits, behaviors, lifestyle, and so on. By proposing an exploratory study, using as an instrument netnography, which deals with the technological mediations adopted in the social context and transposed to the digital network environments to the classic procedures of the research, the study aims to: 1) understand the current configuration of the market of influencers of online social networks in the segment of fashion and beauty in Brazil; 2) to investigate the digital behavior of digital influencers and their followers; 3) analyze the interactions between followers and digital influencers; 4) identify and characterize elements of identity construction around brands from the interactions between influencers and other social actors in the network.

Keywords: Digital influencers; Social networks; Digital behavior.
\end{abstract}

\section{INTRODUÇÃO}

O mercado de bens e serviços vem passando por diversas transformações atualmente. A maneira de fazer marketing e de se comunicar com os clientes também está em transição. O marketing está cada vez mais digital e as empresas vêm sentindo a necessidade de fortalecer sua presença nos ambientes online. Em resposta às demandas da sociedade e de seus públicos-alvo, muitas empresas têm recorrido a novas ferramentas de divulgação na Internet, como os influenciadores digitais.

Os influenciadores digitais usam seus perfis nas redes sociais digitais (Facebook, Instagram, Twitter, YouTube etc.) para conversar com seu público sobre pautas cotidianas, incluindo hábitos de consumo. São indivíduos que exercem impacto acima da média num segmento, seja ele grande pequeno ou mesmo um nicho, capaz de utilizar de sua marca forte para formar um público fiel e engajado, monetizando por meio de seus conteúdos, tendo, assim, grande valor de troca para empresas de diversos segmentos. Desta forma, como empreendedor digital, um influenciador consegue agregar valor e importância a outras marcas, seja de pequenas empresas ou até mesmo organizações já consolidadas no mercado. Essas empresas se utilizam da popularidade, relevância e credibilidade dos influenciadores digitais para conversar com seu publico alvo. Para Safko e Brake (2010) "influência é o alicerce sobre o qual todas as relações economicamente viáveis são construídas".

No Brasil estima-se que existam hoje cerca de 230 mil influenciadores digitais, trabalhando, impulsionando consumo e gerando resultados para a economia do país. O mercado de influenciadores digitais ainda está se desenvolvendo e amadurecendo no país. Neste momento é difícil para as empresas que contratam esse tipo de mídia medir sua efetividade. Por ser novo, o mercado não possui regulamentação, não há garantias nem fórmulas prontas. 
Um estudo mercadológico de 2016 da empresa YOUPIX (plataforma brasileira voltada para discutir a cultura da Internet), em parceria com outras duas empresas especializadas em marketing digital e métricas no mercado brasileiro, conseguiu mapear o mercado dos influenciadores digitais no Brasil e levantar dados que possibilitam um maior entendimento do conceito, mercado atual, perfil e áreas de atuação (Youpix, 2016). Dentre alguns pontos levantados, a pesquisa apontou que existem hoje cerca de 230 mil influenciadores digitais somente no Brasil. Destes, $40 \%$ são mulheres e $60 \%$ homens. Mostrou, também, que $2 \%$ dos influenciadores digitais são responsáveis por $54 \%$ das interações nas redes. Isso se dá porque esses $2 \%$ representam os influenciadores com maior número de seguidores nas redes, maior popularidade e audiência.

Um ponto importante a ser considerado quando se fala de influenciadores digitais ou de popularidade nas redes, requer entender que atualmente a popularidade é medida pela quantidade de seguidores, interações como curtidas e comentários, por exemplo, mas que essa popularidade nas redes sociais pode ser comprada. Existem diversas maneiras de conseguir mais seguidores, comentários, curtidas, visualizações etc. Tais práticas não só minam o mercado como também contribuem para a sensação de incerteza, quando se trata de mensurar a efetividade e o retorno para as empresas contratantes.

Ao investigar a compra de popularidade nas redes pela Internet é possível descobrir um verdadeiro "mercado negro", no qual é possível encontrar aplicativos, agências e até mesmo empresas com diversos dispositivos interligados que realizam ações em massa sob comando de computadores, conhecidos como "fazendas de likes". Estes são apenas alguns exemplos de como é "fácil fazer sucesso nas redes". Com estes aparatos, obter seguidores, curtidas, views (visualizações) e até mesmo comprar comentários com elogios, por exemplo, fica muito mais fácil. Neste sentido é importante refletir quanto à veracidade das informações nas redes sociais. Como confiar nos números que vemos nos perfis? Indo mais fundo na reflexão, como uma empresa poderá acreditar e investir seus orçamentos em parcerias com influenciadores? Por este motivo, bem como pela necessidade de compreensão deste fenômeno, fazem-se necessários estudos acerca dos influenciadores digitais como atores indutores de consumo, como integrantes ativos na economia e nas redes sociais digitais.

Sintetizando de forma mais objetiva esta problemática, o presente estudo se propõe a responder à seguinte questão: Como os influenciadores digitais colaboram na construção identitária em torno de marcas na Internet? Para responder a esta questão e circunscrevendo o estudo deste trabalho a um segmento específico de mercado no Brasil, o objetivo geral deste trabalho é identificar e descrever como se dá a construção identitária em torno de marcas do segmento de moda e beleza brasileiras na Internet promovidas por influenciadores digitais. Especificamente, objetiva-se:

a) Compreender a configuração atual do mercado de influenciadores de redes sociais online no segmento de moda e beleza no Brasil;

b) Investigar o comportamento digital de influenciadores digitais e seus seguidores;

c) Analisar as interações entre seguidores e influenciadores digitais;

d) Identificar e caracterizar elementos de construção identitária em torno de marcas a partir das interações entre influenciadores e outros atores sociais na rede.

O estudo do tema influenciador digital no ambiente mercadológico se justifica por oportunizar a academia contribuições para construção do conhecimento. Para a sociedade, pois os influenciadores estão mudando as dinâmicas do mercado e atuando até mesmo como um novo modelo de negócios, que ainda está se desenvolvendo e precisa de estruturação.

\section{REVISÃO DE LITERATURA}

O avanço tecnológico ocorrido principalmente nos últimos dois séculos (período Pós-Revolução Industrial) é considerado por Schumpeter (1984) como um processo de "destruição criativa", o que para ele caracteriza e define o capitalismo. Segundo o autor, a concorrência centra-se na inovação provocando um processo de destruição criativa, onde velhas estruturas são substituídas por novas, melhorando a economia e a cadeia como um todo. No decorrer do processo evolutivo da Administração, algumas teorias tratam e reforçam a importância da administração estratégica dentro das organizações como fontes de sobrevivência, fundamentais também na competitividade e inovação.

Segundo Motta (2001), uma das ideias centrais da administração cientifica é a de que o homem é um ser eminentemente racional e que ao tomar uma decisão conhece todos os cursos de ação disponíveis, bem como as consequências da opção por qualquer um deles. Pode-se, assim, escolher sempre a melhor alternativa e maximizar os resultados de sua decisão. Por meio dessa abordagem, passamos à ter visão sistêmica, do todo. Neste cenário, torna-se possível verificar o papel do marketing como uma ferramenta estratégica na tomada de decisão. Segundo Las Casas (2009), o Marketing é a área do conhecimento que compreende todas as atividades referentes às relações de trocas conduzidas para a criação de valor para consumidores, visando atingir determinados propósitos de empresas ou indivíduos por meio de relacionamentos estáveis sempre considerando o ambiente de atuação e o 
impacto que essas relações causam no bem estar da sociedade. Portanto, "é preciso verificar as necessidades do mercado e as disponibilidades internas, ou seja, o que a empresa tem a oferecer deve corresponder, ou até mesmo superar, o que o mercado quer"(Cobra, 2009, p.7). Em um cenário extremamente competitivo e voltado para a inovação como o atual, as empresas e os profissionais de Marketing devem saber atrair os clientes. Kotler (2003) acredita que entre as habilidades mais importantes em desta prática estão comunicação e promoção.

No entanto, com o surgimento da Internet, a partir de 1970, o Marketing vem sofrendo transformações à medida que o numero de internautas vai crescendo. O marketing digital pode ser definido como conjunto de estratégias de marketing e publicidade aplicadas à Internet e ao novo comportamento do consumidor quando está navegando. Não se trata de uma ou outra ação, mas de um conjunto coerente e eficaz de ações que criam um contato permanente de sua empresa com seus clientes. O marketing digital possibilita que seus clientes conheçam seu negócio, confiem nele, e tomem a decisão de compra a seu favor.

Em encontro ao conceito de marketing digital, surgem os influenciadores digitais. No contexto geral, os influenciadores digitais, como componentes das redes sociais e impulsionadores diretos de consumo, são parte de uma nova cultura e estilo de vida. Para Teixeira (2018), os modos de vida contemporâneos são contemplados nos estudos de consumo, entendendo não apenas as relações entre marcas, organizações e consumidores, mas também o tempo e o espaço do sujeito, sua representação, uso e ressignificação dos meios e dispositivos midiáticos.

O estudo das interações mediadas por computador deve partir de uma investigação das relações mantidas, e não dos participantes em separado, ou seja, é preciso observar o que se passa entre os interagentes Primo (2007 com citado em Botelho-Francisco, 2018). Ao encontro ao estudo das interações mediadas por computador, alguns autores como Castells (1999), Levy (1999), Jenkins, Green e Ford (2014), Recuero (2009), por exemplo, têm se dedicado a estudar o ciberespaço, investigando os indivíduos nas redes, inteligência coletiva, cultura participativa, compartilhamento informacional instantâneo e a dinâmica colaborativa na web.

\section{PROCEDIMENTOS METODOLÓGICOS}

Os procedimentos metodológicos são importantes para nortear o pesquisador quanto aos métodos e técnicas que serão adotadas em qualquer estudo cientifico. Desta maneira, Gil (2002) entende que método cientifico é um conjunto de procedimentos intelectuais e teóricos adotados para se alcançar o conhecimento. Diante dos objetivos instituídos, a pesquisa se dá como descritiva e exploratória. Neste sentido, como apresentado por Barquette e Chaoubah (2007, p.24), "o principal objetivo da pesquisa exploratória é entender preliminarmente um problema. Por isso, muitas destas pesquisas iniciam-se com um estudo do tipo exploratório". Do ponto de vista dos procedimentos técnicos, a pesquisa se pauta, num primeiro momento, em revisão bibliográfica, de forma a compreender inicialmente o tema a partir da literatura científica disponível. De acordo com Gil (2010 p. 29), "a pesquisa bibliográfica é elaborada com base em material já publicado. Tradicionalmente, esta modalidade de pesquisa inclui material impresso como livros, revistas, jornais, teses, dissertações e anais de eventos científicos". "A principal finalidade é colocar o pesquisador em contato direto com tudo o que foi escrito, dito ou filmado sobre determinado assunto"Marconi e Lakatos (1999, p. 73). Para, além disso, a pesquisa será executada por meio dos pressupostos e técnicas propostos pela Netnografia, que, de acordo com Moura (2015), é considerada um ramo da etnografia adaptado para apoiar a compreensão das complexidades de nosso tempo. Ela incorpora, assim, as mediações tecnológicas adotadas no contexto social e transpostos para os ambientes digitais em rede aos procedimentos clássicos da pesquisa. Sua realização se dá por meio de etapas: a entrada, a coleta de dados, análise dos dados e interpretação, a validação pelos participantes e a observação, os procedimentos éticos na atuação do pesquisador. Desta forma, as informações geradas pelas redes sociais por meio de seus atores podem contribuir de forma significativa para o desenvolvimento de estudos que possibilitem maior compreensão das relações em torno das redes. Ao propor o estudo define-se o seguinte cronograma de pesquisa para que todos os objetivos propostos bem com as etapas de realização necessárias possam ser cumpridos dentro do período de vinte e quatro meses. O objetivo é demonstrar as etapas e distribuir o tempo disponível para a execução do projeto de dissertação de mestrado aqui proposto, conforme Figura 1. Tal cronograma apresenta as etapas a serem realizadas desde o ingresso ao programa de pós-graduação até a defesa.

Cabe salientar que o cronograma acima apresenta apenas uma estimativa, elaborada em primeiro momento para nortear a pesquisa, podendo ser alterado.

\section{CONSIDERAÇÕES PARCIAIS}

Esta proposta de pesquisa pretende trazer contribuições para o conhecimento científico sobre o tema influenciadores digitais, bem como possibilitar e servir como base para pesquisas futuras no ambiente acadêmico e mercadológico, dessa forma proporcionando maior entendimento sobre o que é um influenciador digital, como ele pode agregar nas estratégias de mídia e comunicação das empresas e, por fim, como eles conseguem promover o consumo digital. Em segundo momento, o resultado poderá ser fonte para criação de novas abordagens e ferramentas que auxiliem no entendimento, classificação, criação de indicadores, e métricas quantificáveis, como, por exemplo, a 


\begin{tabular}{|c|c|c|c|c|c|c|c|c|c|c|c|c|c|}
\hline \multirow{10}{*}{ 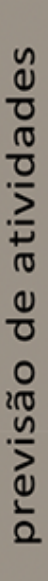 } & ANOS & \multicolumn{4}{|c|}{2018} & \multicolumn{4}{|c|}{2019} & \multicolumn{4}{|c|}{2020} \\
\hline & TRIMESTRE & 1 & 2 & 3 & 4 & 1 & 2 & 3 & 4 & 1 & 2 & 3 & 4 \\
\hline & Cursar créditos obrigatórios & & & & & & & & & & & & \\
\hline & Participação no processo Mestral e Doutoral & & & $x$ & & & & & & & & & \\
\hline & Desenvolver ensaio teórico da dissertação & & & & & & & & & & & & \\
\hline & Desenvolver projeto de pesquisa segundo ensaio teórico & & & & & & & & & & & & \\
\hline & Banca de qualificação & & & & & & & & & & & & \\
\hline & Período de mestrado sanduíche & & & & & & & & & & & & \\
\hline & Elaboração da dissertação, coleta e análise dos dados & & & & & & & & & & & & \\
\hline & Banca de Defesa & & & & & & & & & & & & \\
\hline
\end{tabular}

Figura 1. Cronograma de pesquisa

Fonte: Elaborado pelos autores (2018)

criação de ferramentas que funcionem com metodologia para avaliação da qualidade e perfil de cada influenciador digital, seus segmentos e nichos de mercado, engajamento, retorno para as empresas.

\section{AGRADECIMENTOS}

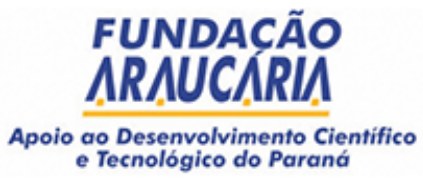

FUNDACÃO

Apoio ao Desenvolvimento Cientifico e Tecnológico do Parana

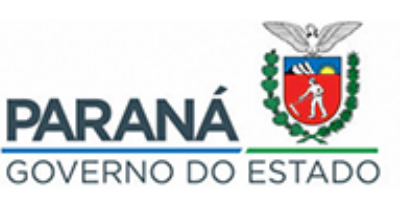

\section{À Fundação Araucária e ao Governo do Estado pelo apoio financeiro para a rea- lização do evento.}

\section{REFERÊNCIAS}

Barquette, S., \& Chaoubah, A. (2007). Pesquisa de marketing (2a ed.). São Paulo: Saraiva.

Botelho-Francisco, R. (2018). Netnografias da Comunicação em Rede: por uma antropologia do comportamento digital. In A. Azevedo Jr., Reflexões sobre mídia e consumo/organizada. Curitiba: Syntagma Editores.

Cobra, M. (2009). Administração de marketing no Brasil (3a ed.). Rio de Janeiro: Elsevier.

Gil, A. (2002). Como elaborar projetos de pesquisa (4a ed.). São Paulo: Atlas.

Gil, A. (2010). Como elaborar projetos de pesquisa (5a ed.). São Paulo: Atlas.

Kotler, P., \& Serra, A. (2003). Marketing de A a Z (12a ed.). Rio de Janeiro: Campus.

Las Casas, A. (2009). Marketing: conceitos, exercícios, casos (8a ed.). São Paulo: Atlas.

Marconi, M. A, \& Lakatos, E. M. (1999). Técnicas de Pesquisa: planejamento e execução, amostra e técnicas, elaboração, análise e interpretação de dados (4a ed.). São Paulo: Atlas.

Motta, F. (2001). Teoria geral da administração (22a ed.). São Paulo (SP): Thomson Pioneira.

Moura, M. (2015). Netnografia: a realidade social sob o véu digital. In R. Araujo. Estudos métricos da informação na web: atores, ações e dispositivos informacionais. Maceió: EDUFAL.

Safko, L., \& Brake, D. (2010). A bíblia da mídia social. São Paulo: Blucher.

Schumpeter, J. (1984). Teoria do desenvolvimento (2a ed.). São Paulo: Nova Cultural.

Teixeira, C., Filho. (2018). Comunicação e consumo no contexto digital: o comportamento mediado e midiatizado. In A. Azevedo Jr. Reflexões sobre mídia e consumo/organizada. Curitiba: Syntagma Editores.

Youpix. (2016). Influencers market. Recuperado de https://medium.youpix.com.br/pesquisa-youpix-influencersmarket-2016-23a71e50fa13 